\title{
3D simulation on convective drying process for cylindrical tea particle using CFD software to analyze the heat and mass transfer phenomena
}

Cite as: AIP Conference Proceedings 2248, 050005 (2020); https://doi.org/10.1063/5.0013452 Published Online: 17 July 2020

Eflita Yohana, Nazaruddin Sinaga, Haryo Pachusadewo, M. Irfan Nugraha, M. Endy Yulianto, and Vita Paramita

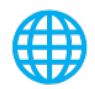

\section{ARTICLES YOU MAY BE INTERESTED IN}

Experimental study of the effects of input voltage on the transient temperature behaviors of thermoelectric mini-cold storage

AIP Conference Proceedings 2248, 070003 (2020); https://doi.org/10.1063/5.0013509

Biodiesel synthesis from used cooking oil using calcium oxide $(\mathrm{CaO})$ catalyst from chicken bones

AIP Conference Proceedings 2248, 060004 (2020); https://doi.org/10.1063/5.0018912

Preliminary study on low pressure hydrothermal liquefaction processes of biomass for biofuels: Bio crude oil

AIP Conference Proceedings 2248, 060002 (2020); https://doi.org/10.1063/5.0013467

\section{Lock-in Amplifiers up to $600 \mathrm{MHz}$}



\title{
3D Simulation on Convective Drying Process for Cylindrical Tea Particle Using CFD Software to Analyze The Heat and Mass Transfer Phenomena
}

\author{
Eflita Yohana ${ }^{1, \text { a) }}$, Nazaruddin Sinaga ${ }^{1}$, Haryo Pachusadewo $^{1}$, M Irfan Nugraha $^{1}$, \\ M Endy Yulianto², Vita Paramita ${ }^{2}$ \\ ${ }^{I}$ Department of Mechanical Engineering, Diponegoro University, Jl. Prof. Sudharto, SH., Semarang 50275, \\ Indonesia \\ ${ }^{2}$ Department of Chemical Engineering, Vocational School, Diponegoro University, Jl. Prof. Sudharto, SH., \\ Semarang 50275, Indonesia \\ a)Corresponding author: efnan2003@gmail.com
}

\begin{abstract}
One of the tea processing that affects the quality of tea is the drying process. The tea drying process was simulated using CFD software to get temperature distribution of tea also determine the optimal value of velocity and temperature inlet. The tea drying simulation is carried out on cylindrical tea, which has a size of $\mathrm{D}=3.5 \mathrm{~mm}$ and $\mathrm{p}=14$ $\mathrm{mm}$ by placing tea material on the computational domain of external flow. Tea Drying Simulation uses inlet velocity and inlet temperature variations. Variations in velocity used are $2.5 \mathrm{~m} / \mathrm{s}, 3.5 \mathrm{~m} / \mathrm{s}$, and $4.5 \mathrm{~m} / \mathrm{s}$, while the temperature variations used are $87^{\circ} \mathrm{C}, 92^{\circ} \mathrm{C}$, and $97^{\circ} \mathrm{C}$. The flow model used is laminar flow. The results showed to achieve the condition of moisture content of tea particles to $5 \%(1.5 \mathrm{~g})$ the fastest drying time occurs at velocity of $4.5 \mathrm{~m} / \mathrm{s}$ with the temperature of $97^{\circ} \mathrm{C}$ is about 348 seconds, while the slowest drying time occurs at velocity $2.5 \mathrm{~m} / \mathrm{s}$ with an inlet temperature of $87^{\circ} \mathrm{C}$ is around 652 seconds.
\end{abstract}

Keyword : Convective drying, CFD simulation, Simultaneous heat and moisture transfer, Optimum drying time.

\section{INTRODUCTION}

Plantations are one of the agricultural sectors that have an important role in Indonesia's economic activities. One of the most significant plantation products in Indonesia is tea, tea agro-industry in Indonesia has been recorded as the largest foreign exchange earner in the national economy. Tea plantations in Indonesia today are in a declining condition because farmers switch from growing tea to coffee, palm oil, cocoa, and other garden crops. The shift of farmers in planting is caused by the decline in global tea prices at the world level. The decline in tea production in Indonesia can be seen from the decrease in the tea planting area from 2002 to 2009 , which only left 126,251 Ha. The causes such as low crop productivity, limited mastery of technology, and farmers as business actors have not been able to follow the standards recommended by GAP (Good Agriculture Practice), GMP (Good Manufacture Process), and quality standards required by ISO [1]. The desired product standard can be achieved in one way is to improve the quality of the tea produced. One of the processes in tea processing that affects the quality of the tea produced is in the drying process.

Types of drying processes include convective drying, indirect or contact drying, electric or microwave drying [2], freeze drying and natural air drying . Convective drying is the most widely used drying method in industries such as agriculture, food industry, building materials, ceramic industry, paper industry, mining waste treatment, etc. 
In general, the convection drying process is influenced by the temperature of the inlet air, the speed of the air flow, the coefficient of displacement etc. Therefore, it is necessary to analyze these properties in convection drying.

Research to solve problems in convection drying related to the distribution of temperature and humidity in humid objects has been carried out. Kaya et al. [3] developed a numerical model of heat and mass transfer during convective drying of 2D rectangular [3] and cylindrical moist objects with the convective boundary conditions and variable heat transfer coefficients along the product surfaces.

In this study, the principle of convective drying was used to dry tea where tea was modeled in cylindrical particles and simulated using CFD software. The purpose of the modeling is to find out the temperature distribution of tea and then calculate it to determine the optimal flow velocity and temperature to improve the quality of the tea produced.

The purpose of this study is to obtain an effective drying time and determine the fastest drying rate, find the heat transfer coefficient.

\section{EQUATION}

\section{Heat Transfer}

Heat transfer that occurred in the fluidized bed dryer is convection. Convection is heat transfer followed by the transfer of particles. convection heat transfer rates can be calculated using equations.

$$
\dot{Q}_{c o n v}=h A_{s}\left(T_{s}-T_{\infty}\right)
$$

\section{Mass diffusion}

The law of Fick diffusion, proposed in 1855, states that chemical species at a location in a gas mixture (liquid or solid solution) are proportional to the gradient of the same species in that location. The concentration of species can be expressed in several ways, namely as follows.

One pair of substances with the most application in mass diffusion is water vapor and dry air. In particular, the equation of the pair diffusion mass coefficient was formulated by Marrero and Mason.

$$
D_{\mathrm{H}_{2} \mathrm{O}-\mathrm{Air}}=1,87 \times 10^{-10} \frac{\mathrm{T}^{2,072}}{P}\left(\mathrm{~m}^{2} / \mathrm{s}\right), \quad 280 \mathrm{~K}<T<450 \mathrm{~K}
$$

\section{Mass convection}

Mass convection is mass transfer that occurs on the surface bordering the flowing fluid caused by mass diffusion.

$$
\dot{m}_{\text {conv }}=h_{\text {mass }} A(\rho A, s-\rho A, \infty)=h_{\text {mass } \rho A} A\left(w A, s-w_{A, \infty}\right)
$$

Mass flux for species A can be stated in the following equation

$$
\dot{j}_{A}=\dot{m}_{A} / A
$$

The relative magnitude of momentum diffusivity and thermal diffusivity in the layers of the speed limit and thermal boundary layer are expressed by the Prandtl number. Whereas in mass convection, the relative magnitude of momentum diffusivity and mass diffusivity in the layer speed limit and concentration boundary layer are expressed by Schmidt numbers. 


$$
\begin{aligned}
& \text { Prandtl Number :Pr } \quad=\frac{v}{\alpha}=\frac{\text { momentum diffusifity }}{\text { termal diffusifity }} \\
& \text { Schmidt Number :Sc } \quad=\frac{v}{D_{A B}}=\frac{\text { momentum diffusifity }}{\text { mass diffusifity }}
\end{aligned}
$$

From these numbers, we can determine the relative amount of thermal diffusivity and the diffusivity of mass in the thermal boundary layer and the concentration boundary layer expressed by the Lewis number.

$$
\text { Lewis Number : Le }=\frac{S c}{P r}=\frac{v}{D_{A B}}=\frac{\text { termal diffusifity }}{\text { mass diffusifity }}
$$

In convection analysis, Calculation of heat transfer and convection mass coefficients will be easier in nondimensional forms. Nusselt and Sherwood numbers represent the effectiveness of heat convection and surface mass [4].

$$
\begin{array}{lll}
\text { Nusselt Number }: & N u & =\frac{h_{\text {conv }} L}{k} \\
\text { Sherwood Number : } & S h & =\frac{h_{\text {mass }} L}{D_{A B}}
\end{array}
$$

To calculate the heat transfer and convection mass coefficients can also use the Stanton number.

$$
\begin{gathered}
\text { Stanton number heat transfer : St }=\frac{h_{\text {conv }}}{\rho \nu C_{p}}=N u \frac{1}{\operatorname{RePr}} \\
\text { Stanton number mass transfer : } S t_{\text {mass }}=\frac{h_{\text {mass }}}{v}=S h \frac{1}{\underline{\operatorname{ReSc}}}
\end{gathered}
$$

\section{RESEARCH METHOD}

The main purpose of the tea drying process is maintaining tea quality so that when it arrives at the consumer, the character is not much different from the time out of the drying process. However, this is difficult to achieve because tea is hygroscopic and generally during the process of sorting, packing, and transportation, the moisture content of tea can reach more than $15 \%$ so that the enzymatic oxidation reaction persists. Therefore drying the tea must be carried out to specified moisture content. Moisture content in tea is around $60-70 \%$ before drying. This moisture content reaching $60-70 \%$ was previously carried out withering and had to be reduced to $5-15 \%$ after drying [5]. 
(a)

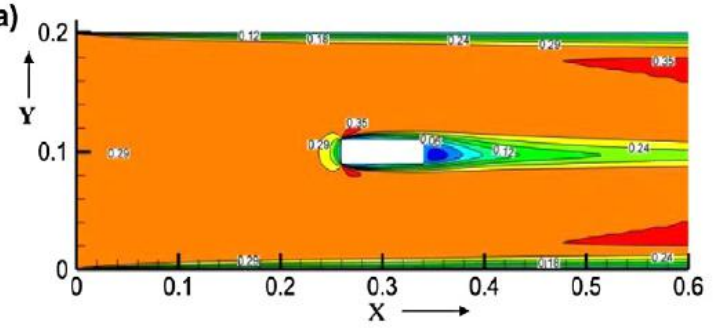

(b)



FIGURE 1. (a) Velocity contour and (b) Temperature contour XY field at $Z=0.01 \mathrm{~m}$ around moist object [6]

Then the contour is compared with the results of the Validation Simulation as shown in Fig. 3.

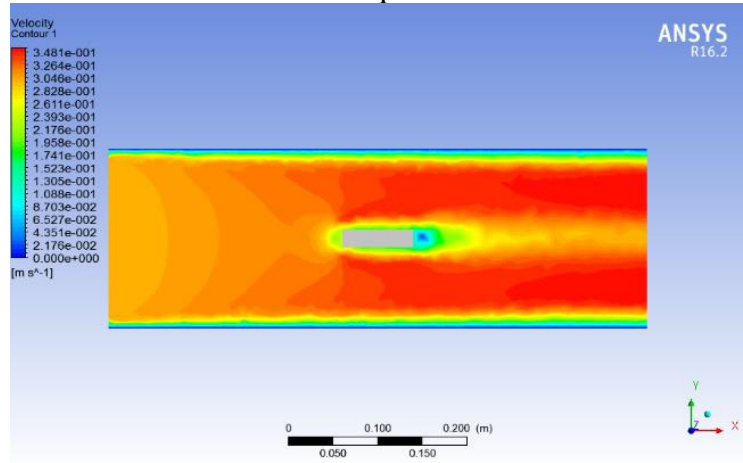

(a)

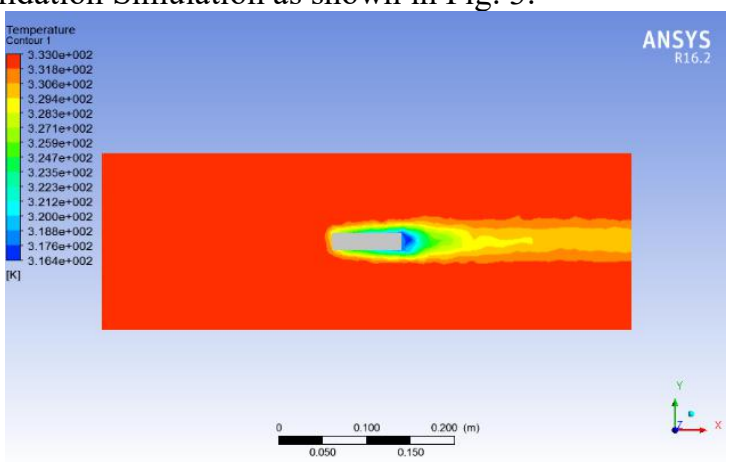

(b)

FIGURE 2. Validation simulation results (a) Velocity

contour and (b) Temperature contour $\mathrm{XY}$ field at $\mathrm{Z}=0.01 \mathrm{~m}$ around the moist object

Figures 2 and 3 show the suitability of the velocity contour where there are areas with higher velocity values on the outlet side of the computational domain, while the lower velocity values are in the area behind the material of the moist object and the outermost side of the computational domain. Then, on the temperature contour, the simulation results also show compatibility where there are areas with higher temperature values in the inlet side of the computational domain, while the lower temperature values are found in the area behind the material of the moist object. Furthermore, validation of the temperature distribution values along the $X$ field of the moist object $(\mathrm{Y}=0.01 \mathrm{~m}$ and $\mathrm{Z}=0.01 \mathrm{~m})$ as shown in Fig. 4 . 


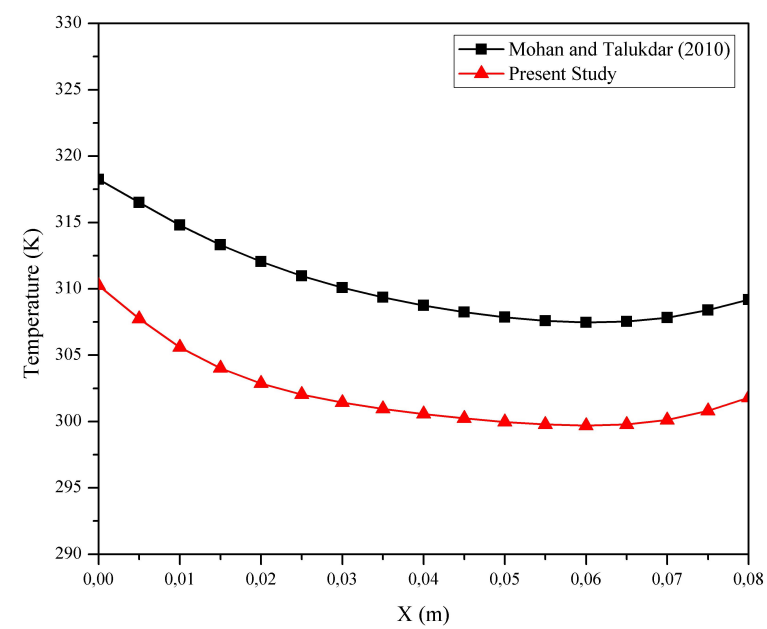

FIGURE 3. Validation of the temperature distribution values along the $\mathrm{X}$ field of moist object $(\mathrm{Y}=0.01 \mathrm{~m}$ and $\mathrm{Z}=0.01 \mathrm{~m})$

From Fig. 4 the graph of the temperature distribution along the $\mathrm{X}$ field of the moist object having similarities, where the temperature of the moist object facing the inlet side $(x=0 \mathrm{~m})$ has a higher value than the temperature of the moist object facing the outlet side $(\mathrm{x}=0.08 \mathrm{~m})$. The simulation error value is $2.633 \%$. Also, a validation of the average temperature values of the moist object during the drying process, as shown in Fig. 5.

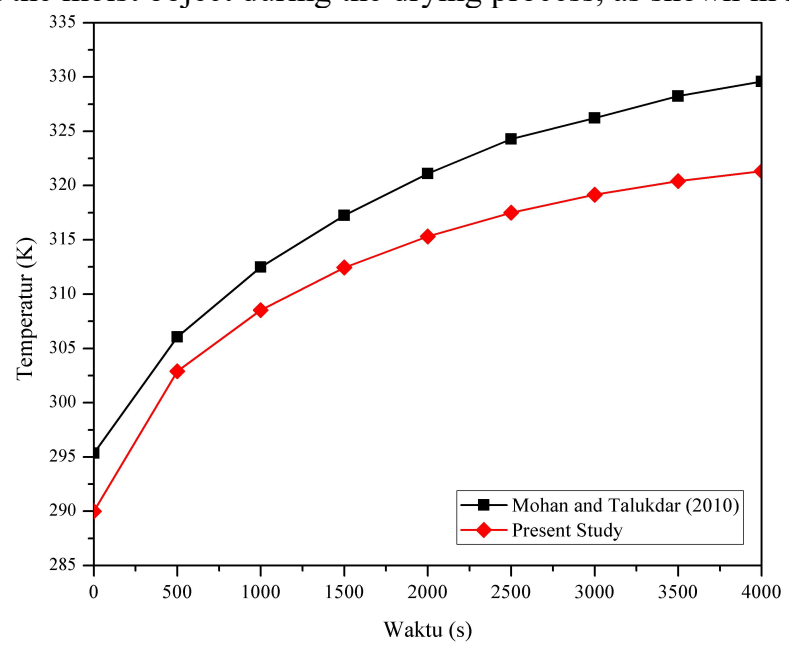

FIGURE 4. Validation of the average temperature of moist object

From Fig. 4, the graph of the average temperature values of a moist object during the drying process, which has similarities, where the average temperature of a moist object increases all the time. The simulation error value is $1.843 \%$.

TABLE 1. Computational Method

\begin{tabular}{ll}
\hline Parameter & \\
\hline Computational Domain & - Pressure-Based \\
General Setting & - Transient \\
& - Energy Equation: Active \\
Model & - Viscous Model: Laminar \\
& - Species Transport: Active \\
Material & Air: Mixture-Template $\left(\mathrm{H}_{2} \mathrm{O}-\mathrm{Air}\right)$ \\
Boundary Conditions & - Inlet: Velocity Inlet \\
& - Outlet: Pressure Outlet
\end{tabular}




$\begin{array}{ll} & \text { - Computational Domain: Wall } \\ \text { Solution Methods } & \text { - Pressure-Velocity Coupling: Coupled } \\ & \text { - Spatial Discretization: Second-Order Upwind } \\ & \text { - Transient Formulation: First-Order Implicit } \\ & \text { Convergence Characteristics } \\ \text { Residuals Monitor } & \text { - Continuity: } 10^{-3} \\ & \text { - Energy: } 10^{-6} \\ \text { Max Iterations/Time Step } & \text { 20 Iterations }\end{array}$

\section{RESULT AND DISCUSSION}

Based on the results of the Tea Drying Simulation with inlet velocity variations and inlet temperature variations, the results of the temperature distribution of tea particles to the drying time made into the graph. The temperature distribution results in the form of the minimum temperature and the maximum temperature of the tea surface, with this value can be calculated the average temperature of the tea surface used to calculate the value of the film temperature and the difference in the surface temperature of the tea to the inlet temperature, as shown in Fig. 6.

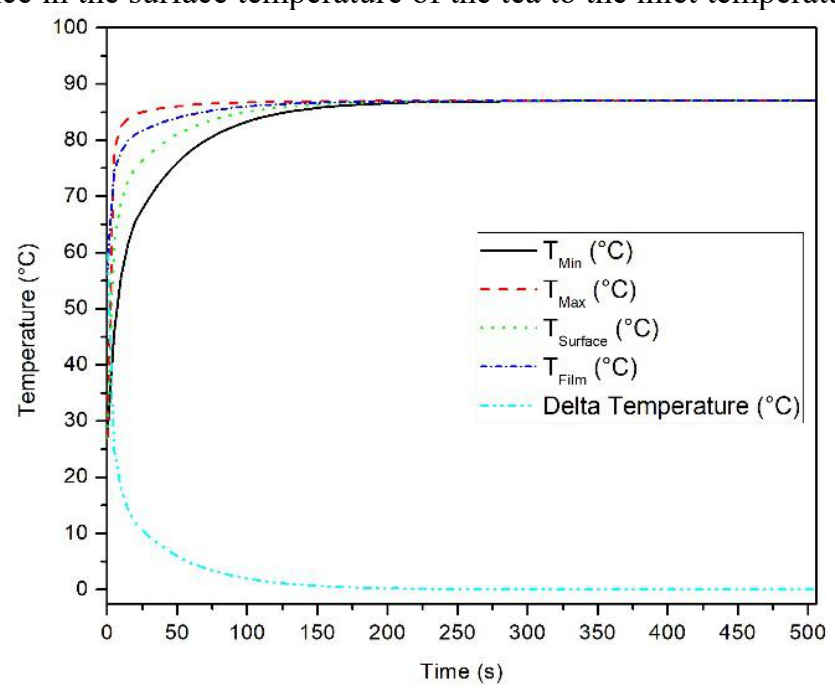

FIGURE 5. Temperature distribution at $\mathrm{v}_{\text {Inlet }}=2.5 \mathrm{~m} / \mathrm{s}$ and $\mathrm{T}_{\text {Inlet }}=87^{\circ} \mathrm{C}$

From Fig. 5, it can be seen the temperature distribution at the variation of inlet velocity of $2.5 \mathrm{~m} / \mathrm{s}$ and inlet temperature of $87^{\circ} \mathrm{C}(360 \mathrm{~K})$. At the fifth second of drying, the value of the minimum and maximum surface temperature of the tea is $45.750^{\circ} \mathrm{C}$ and $78.445^{\circ} \mathrm{C}$. From the temperature value, then the value of the average surface temperature of the tea is $62.098^{\circ} \mathrm{C}$, and the film temperature is $74.549^{\circ} \mathrm{C}$. The temperature value will continue to increase significantly and will be constant near the inlet temperature, and the temperature value reaches a maximum value of $87^{\circ} \mathrm{C}$ at 506 seconds. Very fast temperature rise at the beginning of drying is caused by a significant temperature difference between the inlet temperature and the average surface temperature of tea at the beginning of drying. The value of the tea surface temperature difference in the inlet temperature, which was initially valued at $60^{\circ} \mathrm{C}$ will continue to decrease significantly close to $0^{\circ} \mathrm{C}$.

Based on the results of the temperature distribution of tea particles to the drying time, the calculation is done to calculate the heat transfer that occurs during tea drying. The calculation results in the form of heat transfer coefficient, heat transfer rate, and heat transfer rate per unit area (heat flux) to the drying time which is then made into the graph as shown in Fig. 6. 


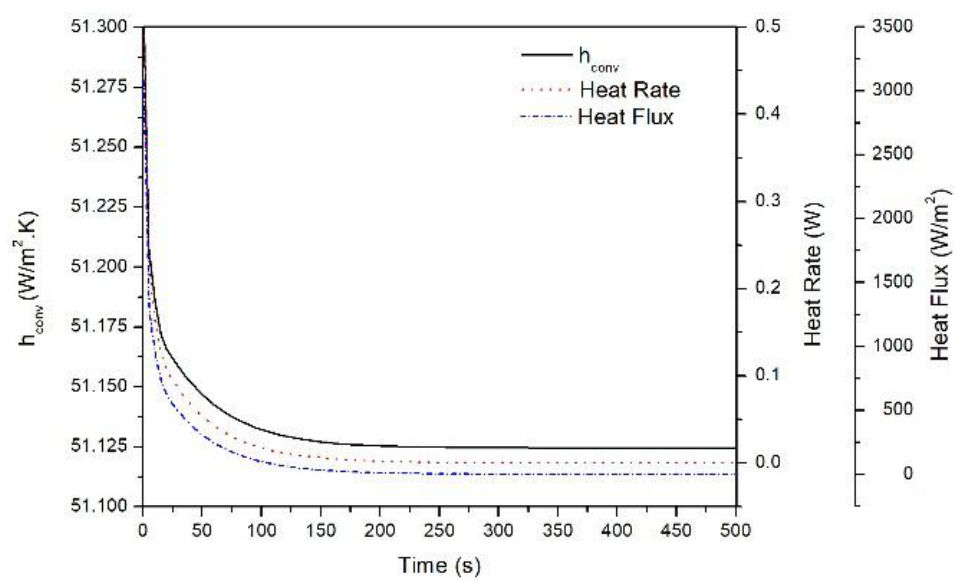

FIGURE 6. Heat transfer at $\mathrm{v}_{\text {Inlet }}=2.5 \mathrm{~m} / \mathrm{s}$ and $\mathrm{T}_{\text {Inlet }}=87^{\circ} \mathrm{C}$

From Fig. 6, it can be seen heat transfer at the variation of inlet velocity of $2.5 \mathrm{~m} / \mathrm{s}$ and inlet temperature of $87^{\circ} \mathrm{C}$ $(360 \mathrm{~K})$. The value of heat transfer coefficient at the beginning of drying is $51.317 \mathrm{~W} / \mathrm{m}^{2} \cdot \mathrm{K}$, this value will continue to decrease and will continuously be approaching the value of $51.125 \mathrm{~W} / \mathrm{m}^{2} . \mathrm{K}$. From the heat transfer coefficient, then the rate of heat transfer that occurs during tea drying using Newton Cooling Law, where at the beginning of the drying rate of heat transfer is $0.533 \mathrm{~W}$ and continues to decrease significantly so that no heat transfer occurs after drying the tea approximately 506 seconds. In addition, it also can be determined the heat transfer rate per unit area that occurs when drying tea or what is called heat flux. The heat flux value at the beginning of drying is valued at $3079.035 \mathrm{~W} / \mathrm{m}^{2}$ and reaches a value of $0 \mathrm{~W} / \mathrm{m}^{2}$ when there is no more heat transfer that occurs in the drying process. This is because the temperature of the tea surface has reached a maximum temperature of $87^{\circ} \mathrm{C}$ so that there is no difference between the surface temperature of the tea to the inlet temperature.

The next step is to calculate the mass transfer that occurs during tea drying. The calculation results in the form of mass transfer coefficient, mass transfer rate, and mass transfer rate per unit area (mass flux) to the drying time which is then made into the graph as shown in Fig. 7.

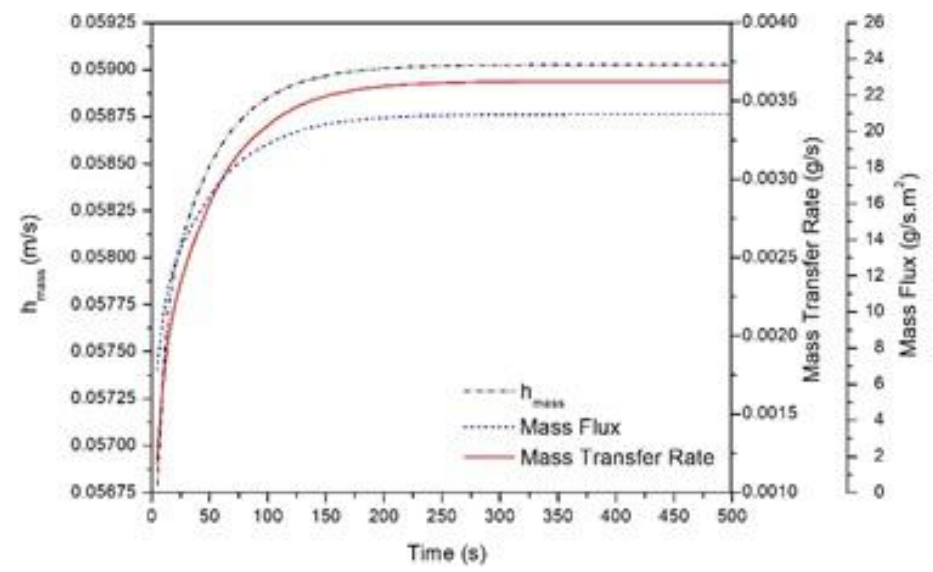

FIGURE 7. Mass transfer at $\mathrm{v}_{\text {Inlet }}=2.5 \mathrm{~m} / \mathrm{s}$ and $\mathrm{T}_{\text {Inlet }}=87^{\circ} \mathrm{C}$

From Fig. 8, it can be seen that mass transfer at the variation of inlet velocity of $2.5 \mathrm{~m} / \mathrm{s}$ and inlet temperature of $87^{\circ} \mathrm{C}(360 \mathrm{~K})$. At the fifth second drying the mass transfer coefficient is valued at $5.679 .10^{-2} \mathrm{~m} / \mathrm{s}$, the mass transfer rate is $1.177 .10^{-3} \mathrm{gr} / \mathrm{s}$, and the mass transfer rate per unit area (mass flux) is $6.799 \mathrm{gr} / \mathrm{s} . \mathrm{m}^{2}$. This value will continue to increase significantly and will be constant near the maximum value after drying the tea is done for approximately 506 seconds. The maximum mass transfer coefficient is $5.903 .10^{-2} \mathrm{~m} / \mathrm{s}$, the maximum mass transfer rate is $3.626 .10^{-3}$ $\mathrm{gr} / \mathrm{s}$, and the maximum mass transfer rate per unit area (mass flux) is $20.936 \mathrm{gr} / \mathrm{s}^{\mathrm{m}} \mathrm{m}^{2}$. The maximum value is due to the temperature of the tea surface has reached a maximum temperature of $87^{\circ} \mathrm{C}$ so that there is no difference 
between the surface temperature of the tea to the inlet temperature. The increase in the mass transfer coefficient is affected by the increase in the average temperature of the tea surface during the drying process.

\section{CONCLUSION}

From the results of the tea drying simulation research using CFD software can be taken some conclusions including during the drying process, the average temperature on the tea surface will continue to increase significantly and will be constant near the inlet temperature, while the tea surface temperature difference to the inlet temperature will continue to decline significantly close to $0^{\circ} \mathrm{C}$. During the drying process, the heat transfer coefficient will continue to decline and will be constant near its minimum value. From the value of the coefficient, then the heat transfer rate and heat transfer rate per unit area (heat flux) can be calculated in the drying of the tea, the value will continue to decline and reach a value of 0 when there is no heat transfer that occurs in the drying process. During the drying process, the mass transfer coefficient, mass transfer rate, and mass transfer rate per unit area (mass flux) will continue to increase significantly and will be constant near their maximum values. The decrease in the mass of tea particles is caused by the reduction of moisture content in the tea particles due to the evaporation of water that occurs during the drying process, where the moisture content of tea particles is initially about $65 \%$ after drying the moisture content of tea particles to $5 \%$. Under these conditions, the tea particle mass was initially around $3.75 \mathrm{~g}$ after the tea particle mass was dried to $1.5 \mathrm{~g}$. To achieve the condition of moisture content of tea particles to $5 \%(1.5 \mathrm{~g})$ the fastest drying occurs at inlet velocity of $4.5 \mathrm{~m} / \mathrm{s}$ and inlet temperature of $97^{\circ} \mathrm{C}$ is around 348 seconds, while the slowest occurs at an inlet velocity of $2.5 \mathrm{~m} / \mathrm{s}$ and inlet temperature of $87^{\circ} \mathrm{C}$ is about 652 seconds.

\section{REFERENCES}

1. Sudjarmoko B, "Perkembangan Pasar Teh Indonesia di Pasar Domestik dan Pasar Internasional," 2014. .

2. M. Al-ali, K. I. Salih, and A. Alsamarrae, "Materials Today : Proceedings Microwave heating temperatures and pharmaceutical powder characteristics," Mater. Today Proc., no. xxxx, 2019.

3. A. Kaya, O. Aydin, and I. Dincer, "Numerical modeling of heat and mass transfer during forced convection drying of rectangular moist objects," Int. J. Heat Mass Transf., vol. 49, no. 17-18, pp. 3094-3103, 2006.

4. R. W.Fox, A. T. McDonald, and P. J.Pritchard, Introduction to Fluid Mechanics. 6th Edition. USA : Purdue University, 2004.

5. T. Anggraini, Proses dan Manfaat Teh. 2017.

6. V. P. Chandra Mohan and P. Talukdar, "Three dimensional numerical modeling of simultaneous heat and moisture transfer in a moist object subjected to convective drying," Int. J. Heat Mass Transf., vol. 53, no. 21-22, pp. $4638-4650,2010$. 